\title{
Predictors of Depressive Symptoms and Post Traumatic Stress Disorder Among Women Engaged in Commercial Sex Work in Southern Uganda
}

\author{
Proscovia Nabunya, PhD. ${ }^{\text {a, }}$, William Byansi, MSW ${ }^{\text {a }}$, Christopher Damulira, BA ${ }^{\text {a }}$, \\ Ozge Sensoy Bahar ${ }^{a}$, Larissa Jennings Mayo-Wilson ${ }^{b}$, Yesim Tozan ${ }^{c}$, Joshua Kiyingi ${ }^{a}$, \\ Josephine Nabayinda ${ }^{a}$, Rachel Braithwaite ${ }^{\mathrm{a}}$, Susan S. Witte ${ }^{\mathrm{d}}$, Fred M. Ssewamala, PhD ${ }^{\mathrm{a}}$ \\ ${ }^{a}$ Washington University in St. Louis Brown School, International Center for Child Health and Development (ICHAD), 1 Brookings Drive, St. Louis, MO 63130, USA \\ ${ }^{\mathrm{b}}$ Indiana University School of Public Health, Department of Applied Health Science, 1025 E. $7^{\text {TH }}$ Street, Bloomington, IN 47405, USA \\ ${ }^{\mathrm{c}}$ New York University College of Global Public Health, 14 East $4^{\text {th }}$ street, $3^{\text {rd }}$ floor. New York, NY 10003, USA \\ ${ }^{\mathrm{d}}$ Columbia University School of Social Work1255 Amsterdam Avenue, New York, NY 10027, USA
}

\section{A R T I C L E I N F O}

\section{Keywords:}

Women engaged in sex work

Depression

Post-traumatic stress disorder

Mental health

Sex work

Uganda

\begin{abstract}
A B S T R A C T
This study examined the factors associated with depressive symptoms and post traumatic depressive disorder (PTSD) among economically vulnerable women engaged in commercial sex work (WESW) in southern Uganda. Baseline data from a longitudinal cluster randomized study involving 542 self-identified WESW (18-55 years), recruited from $19 \mathrm{HIV}$ hotspots were analyzed. Hierarchical linear regression modelling was utilized to estimate individual, family-level and economic-level predictors of depressive symptoms and PTSD. Family cohesion, sex work stigma, HIV status, financial distress, household assets, number of children and number of household income earners, were associated with PTSD. Similarly, family cohesion, number of people in the household, HIV status, sex work stigma, financial distress, and household assets, were associated with depressive symptoms. Women engaged in commercial sex work are at a higher risk of HIV and poor mental health outcomes. Sex work stigma and financial distress elevate levels of depressive symptoms and PTSD, over and above an individual's HIV status. Family and economic-level factors have the potential to mitigate the risk of poor mental health outcomes. As such, integrating stigma reduction and economic strengthening components in the programming targeting WESW-a key population, may be critical to address their mental health outcomes.
\end{abstract}

\section{Introduction}

Mental health disorders are a major cause of disability globally, with more than $80 \%$ of people with these disorders living in low- and middleincome countries (LMICs), including in Sub-Saharan Africa (SSA) (Patel, 2007; Rathod et al., 2017; Yatham et al., 2018). It is estimated that by 2030, depression alone is likely to be the third leading cause of disease burden in low-income countries (Mathers \& Loncar, 2006). Despite the need for mental health services, the treatment gap is large with between $76 \%$ and $86 \%$ of people with severe mental health disorders receiving no treatment in LMICs (Lund et al., 2015; WHO, 2013). Similar to other SSA countries, mental health services in Uganda are underfunded, with less than $1 \%$ of the national health budget allocated to mental health services (Molodynski et al., 2017; WHO, 2018). Moreover, the mental health system is characterized by a shortage of trained personnel (less than $1 \%$ of medical personnel are specialized in psychiatry), inadequate infrastructure (less that 2 beds per 100,000 people in mental health facilities), and outdated mental health laws (Kigozi et al., 2010; Mugisha et al., 2016). This is worsened by high levels of stigma attached to mental health (Audu, et al., 2013; Kapungwe et al., 2010; Ssebunnya, et al., 2009).

Women who commercially exchange sex for money, goods or services, hereafter, women engaged in sex work (WESW) (Ssewamala et al., 2019; UNAIDS, 2002), are highly marginalized and stigmatized, which exacerbates their poor mental health outcomes (Beattie et al., 2020). Studies have documented that WESW experience worse mental health outcomes than the general population, including high rates of anxiety, depression, post-traumatic stress disorder (PTSD), psychological distress

\footnotetext{
* Corresponding Author.

E-mail addresses: nabunyap@wustl.edu (P. Nabunya), byansiw@wustl.edu (W. Byansi), damulirac@wustl.edu (C. Damulira), ozge.sensoybahar@wustl.edu

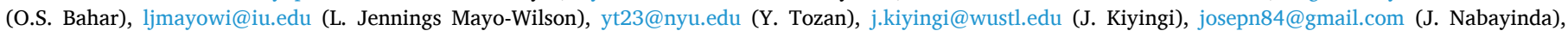
rachel.brathwaite@wustl.edu (R. Braithwaite), ssw12@columbia.edu (S.S. Witte), fms1@wustl.edu (F.M. Ssewamala).
} 
and suicide ideation (Beattie et al., 2020). Unfortunately, most preventive measures among WESW have focused on risk reduction for HIV transmission, ignoring their psychosocial wellbeing and mental health needs (Ampt et al., 2020; Cowan et al., 2018). Yet, poor mental health increases the risk of high-risk sexual behaviors and HIV transmission (Lundberg et al., 2011; Nduna et al., 2010; Smit et al., 2006). Moreover, given that sex work is criminalized in most SSA countries, including in Uganda (Baleta, 2015; Mgbako \& Smith, 2009; Platt et al., 2018), few studies have examined the mental health functioning of WESW in the region (Beattie et al., 2020).

Individual- and structural-level factors perpetuate poor mental health outcomes among WESW. Specifically, poverty, sex work stigma, gender inequality, experiences of physical and sexual violence, child trauma and social exclusion, all increase the risk of poor mental health outcomes (Onyeneho, 2009; Deering et al., 2014; Koenig et al., 2004). Indeed, WESW are exposed to constant harassment, arrests, physical abuse from law enforcement, as well as violence from their clients due to the illegality of sex work (Baleta, 2015; Mgbako \& Smith, 2009; Platt et al., 2018; Sirotin et al., 2010). In addition, the high rates of poverty in SSA, including in Uganda, drive women into commercial sex work (Baleta, 2015; Fielding-Miller et al., 2014). Taken together, these experiences increase the risk of poor mental health outcomes (Beattie et al., 2020). Unfortunately, the lack of access to health care services indicates that those with mental health problems may not be screened or have access to needed care (Parcesepe et al., 2016; Patel \& Kleinman, 2003). Moreover, the stigma associated with sex work and mental health limits WESW from seeking health care services, where available (Baral et al., 2012; Nyblade et al., 2017; Scorgie et al., 2013).

This study examines the individual-level, family-level, and economic-level factors associated with depressive symptoms and PTSD among WESW in the southern region of Uganda. While sex work is illegal in Uganda, the government designates individuals employed by sex work as a key population for HIV prevention and risk reduction programs (Republic of Uganda, 2018; Uganda AIDS Commission, 2015). As such, this is an important area of inquiry, as findings may inform the development and incorporation of mental health services in HIV-related programming targeting WESW - given their particularly high levels of vulnerability in low-resource settings.

\section{Methods}

\subsection{Sample and Setting}

This study utilized baseline data from the Kyaterekera Project (20182023), a longitudinal randomized clinical trial funded by the National Institute of Mental Health (NIMH). Primarily, the trial aims to evaluate the efficacy of adding economic empowerment components to traditional HIV risk reduction (HIVRR) to reduce new incidences of sexually transmitted infections (STIs) and HIV among WESW in the greater Masaka region of Uganda (Ssewamala et al., 2019). Women were eligible to participate if they met the following conditions: 1) 18+ years; 2) reported engagement in unsafe transactional sex (defined as a sex act in exchange for pay) in the past 30 days; and 3) reported engagement in one or more episodes of unprotected sex in the past 30 days, with either a paying, casual or regular sex partner (Ssewamala et al., 2019).

A total of 542 self-identified WESW (ages 18 to 55), were recruited from 19 comparable HIV hotspots (sites) located in 7 districts, namely, Masaka, Lwengo, Kyotera, Rakai, Mpigi, Kalungu, and Lyantonde, in the southern region of Uganda. While Uganda has registered declined HIV prevalence (5.8\%) among 15-49 years-old in 2019, the overall prevalence in the study region is higher than the national average, ranging between $8.7 \%$ to $11.3 \%$, with Masaka (11.3\%) and Kyotera $(10.8 \%)$ reporting the highest prevalence (Uganda AIDS Commission, 2020). In addition, the HIV prevalence among WESW in Rakai and Masaka districts alone is as high as $61 \%$ (Ssembatya et al. 2015).

\subsection{Participant Recruitment}

We engaged community stakeholders currently working with WESW in the study region to identify potential recruitment sites. These included towns/HIV hotspots along major boarder highways, as well as fishing villages and landing sites along Lake Victoria - major places where WESW seek economic opportunities, but with HIV prevalence rates of 22\% or higher (Kamali et al., 2016; Morris \& Ferguson., 2006; Opio et al., 2011; Seeley et al., 2009). The research team obtained contact information of key individuals -hereafter site coordinators, at each potential site. We utilized respondent-driven sampling and snowball sampling - recruitment approaches recommended for hard-to-reach populations, including WESW (Goel and Salganik, 2009; Okal et al., 2016). Specifically, the research team met with site coordinators at their respective sites to provide them with information about the study. Site coordinators were also able to advise on the best times and location to meet with potential participants, total number of WESW at their respective sites, health services available, including ongoing research programs and interventions.

Following the one-on-one meetings, site coordinators then helped to mobilize other WESW in their networks. Interested WESW were invited for a one-on-one informational meeting with the research team and were taken through a two-level informed consent process. All WESW who turned up provided consent to be screened for eligibility. Those who met the inclusion criteria were taken through another informed consent process to participate in the study. Specifically, WESW were informed verbally and in writing, the purpose of the study, voluntary participation, extent of their participation, risks and benefits, as well as protection and confidentiality issues. Interested WESW signed the informed consent. Those who were unable to make a decision right away were given up to one week to decide. All participants who provided consent were then allowed to complete baseline assessments and biomarker testing. Between June 2019 to March 2020, a total of 890 women from 19 sites were screened for eligibility; of these, 542 met the inclusion criteria, provided informed consent, and were enrolled into the study.

\subsection{Ethical Considerations}

All study procedures were approved by the Washington University in St. Louis Institutional Review Board (\#201811106), Columbia University Institutional Review Board (AAAR9804), and the in-country local IRBs in Uganda: Uganda Virus Research Institute (UVRI) Research Ethics Committee (GC/127/18/10/690) and the Uganda National Council of Science and Technology (UNCST -SS4828). Informed voluntary written consent was obtained from all study participants prior to participation.

\subsection{Data Collection and Measures}

Measures utilized in this study were tested in our previous studies among young people affected by HIV and among their caregivers in the study region (Kagotho et al., 2012; Han et al., 2013; Nabunya et al., 2014; Wang et al., 2014; Ssewamala et al., 2009), and in prior studies conducted among WESW (Tsai et al., 2018; 2011; Mergenova et al., 2019; Witte et al., 2015,2011). Data were collected using a 90-minute interviewer administered survey. Survey instruments were translated into Luganda - the most widely spoken language in the study region and back translated into English to ensure accuracy. Certified language experts at the Makerere University in Uganda oversaw this process. Each interviewer received Good Clinical Practice training and obtained the Collaborative Institutional Training Initiative (CITI) Human Subjects Certificate before interacting with study participants. As part of study procedures, all recruited participants went through biomarker testing for HIV, CD4 and STIs (Gonorrhea, Chlamydia and Trichomonas), conducted by registered nurses. 


\subsubsection{Outcome Variables}

Depressive symptoms were measured using the six-item subscale of the Brief Symptom Inventory (BSI) (Derogatis \& Melisaratos, 1983). Item responses were ranked based on severity on a 5-point continuum $(1=$ Not at all and $5=$ Extremely). The subscale demonstrated a high reliability (Cronbach's alpha $=0.82$ ). The theoretical range for this scale is 6-30, with higher summated scores indicating higher levels of depressive symptoms. Post-traumatic stress disorder (PTSD) was measured using six items adapted from the abbreviated PTSD checklist (Lang \& Stein, 2005). Responses were rated on a 5-point Likert scale, with $1=$ Not at all and $5=$ Extremely. The scale yielded a high reliability (Cronbach's alpha $=0.84$ ). The theoretical range for this scale is 6-30, with higher summated scores indicating higher levels of PTSD symptoms.

\subsubsection{Individual- and Family-level Factors}

These include participants' age, level of education, marital status, HIV status, household composition i.e., total number of people and number of children in the household, family cohesion, feel safe in current home, history of being arrested, domestic violence attitudes, sex work stigma, number of days engaged in sex work per week, and number of paying sexual partners in the past 30 days.

Family cohesion was measured using seven items adapted from the Family Environment Scale (Moos, 1994) and the Family Assessment Measure (Skinner et al., 2009) that assesses the degree of commitment, help, and support that family members provide to one another. Responses were rated on a 5 -point Likert scale, with $1=$ Never and $5=$ Always. The theoretical range for this scale is $7-35$, with high summated scores indicating higher levels of family cohesion (Cronbach alpha $=0.85)$. Sex work stigma was measured using the Sex Worker Stigma Index (Liu et al., 2011). Responses were rated on a 4-point Likert scale, with $1=$ Strongly disagree to $4=$ Strongly agree. The scale yielded a high reliability (Cronbach's alpha $=0.92$ ). The theoretical range for this scale is $10-40$, with higher summated scores indicating higher levels of sex worker stigma. Domestic violence attitudes were measured using five items assessing whether a man/husband would be justified in beating or hitting their spouse (Stark et al., 2018). Responses were binary coded with No $=0$ and Yes $=1$, with high scores indicating high levels of domestic violence attitudes.

\subsubsection{Economic level Factors}

These were measured by the following indicators: 1) financial distress was measured by five items assessing the ability to access basic needs, including money to buy food, clothing, transportation, housing fees/rent, and health or medical expenses $(1=$ Never and $4=$ Many times); 2) household assets were measured using a 21-item index assessing the availability of assets (e.g., land, a house, means of transportation, gardens, or means of communication). A high index score indicates a larger number of assets owned by the participant's household; 3) currently working for pay; and 4) number of income earners in the household.

\subsection{Data Analysis Procedures}

All analyses were conducted using Stata software version 12.1 (StataCorp LP, College Station, TX, USA). First, we conducted descriptive analyses for all the predictors and outcome variables. Second, hierarchical regression models were conducted to determine the predictors of depressive symptoms and PTSD. For each outcome, we conducted two models, with each model controlling for a block of predictors. Model 1 controlled for individual- and family-level factors, and model 2 controlled for economic-level factors. Adjusted R squares were compared to determine the strength of each model.

\section{Results}

Sample characteristics are summarized in Table 1 . The average age
Table 1

Sample Characteristics

\begin{tabular}{|c|c|}
\hline Variable & $\begin{array}{l}\text { Total Sample }(\mathrm{N}=542) \\
\%(\mathrm{n})\end{array}$ \\
\hline \multicolumn{2}{|l|}{ Individual and household level factors } \\
\hline HIV status (positive) & $41(220)$ \\
\hline \multicolumn{2}{|l|}{ Age (Min/Max: 18-55) } \\
\hline $18-24$ & $18.8(102)$ \\
\hline $25-34$ & $47.6(258)$ \\
\hline $35+$ & $33.6(182)$ \\
\hline \multicolumn{2}{|l|}{ Marital Status } \\
\hline Married/In a relationship & $25.6(139)$ \\
\hline Single & $13.3(72)$ \\
\hline Other (divorced, separated, widowed) & $61.1(331)$ \\
\hline \multicolumn{2}{|l|}{ Level of education } \\
\hline Primary school education & $87.7(473)$ \\
\hline High school education & $12.7(69)$ \\
\hline \multicolumn{2}{|l|}{ Household Composition } \\
\hline Number of people in the household (Min/Max: 1-18) & $3.6(2.2)$ \\
\hline Number of children in the household (Min/Max: $0-10$ ) & $1.8(1.7)$ \\
\hline Family cohesion (Min/Max: 7-35) & $17.5(7.0)$ \\
\hline Feel safe at home & $84.5(458)$ \\
\hline Ever been arrested & $24.9(135)$ \\
\hline Sex work stigma (Min/Max: 10-40) & $29.8(7.8)$ \\
\hline Domestic violence attitudes (Min/Max: 0-5) & $2.9(1.6)$ \\
\hline $\begin{array}{l}\text { Days of the week do you engage in sex work (Min/Max: } \\
1-7 \text { ) }\end{array}$ & $5.1(1.8)$ \\
\hline $\begin{array}{l}\text { Number of different customers in the past } 30 \text { days (Min/ } \\
\text { Max: 0-280) }\end{array}$ & $33.4(47.4)$ \\
\hline \multicolumn{2}{|l|}{ Economic level factors } \\
\hline Financial distress (Min/Max: 4-20) & $14.4(4.5)$ \\
\hline Household Asset Index (Min/Max: 0-19) & $5.52(5.2)$ \\
\hline Currently working for pay & $23.6(128)$ \\
\hline $\begin{array}{l}\text { Number of income earners in the household (Min/Max: } \\
0-4)\end{array}$ & $0.9(0.6)$ \\
\hline \multicolumn{2}{|l|}{ Outcome Variables } \\
\hline PTSD (Min/Max: 6-30) & $13.7(5.9)$ \\
\hline Depressive Symptoms (Min/Max: 6-30) & $10.9(4.9)$ \\
\hline
\end{tabular}

Note: ${ }^{*} \mathrm{p} \leq .05 ; * * \mathrm{p} \leq .01 ; * * * \mathrm{p} \leq .001$

was 31.4 years, the majority of participants were between $25-34$ years (47.6\%). Of the total sample ( $\mathrm{N}=542), 42 \%$ of participants tested HIV positive. Participants lived in households with about 4 people and 2 children under 18 years of age. Less than one half $(25.6 \%)$ of participants were married. Over $87 \%$ had some primary school education. The majority of participants (84\%) reported feeling safe in their current home, and about $25 \%$ reported a history of being arrested. The average score on the measure of family cohesion was 17.5 , the sex work stigma index was 29.5, and the domestic violence attitudes score was 2.9. In addition, the average score on the measure of financial distress was 14.4, and the household asset index was 5.52. Only $23.6 \%$ of the participants were currently working for pay (in addition to sex work), with one additional income earner in the household. On average, participants reported engaging in sex work 5 days a week, with an average of 33 paying sexual partners in the past 30 days. The average score on the PTSD measure was 13.7 , and the average score on the measure of depressive symptoms was 10.9 .

Results from hierarchical regression analyses are presented in Table 2. In model 1, we controlled for individual- and family-level factors (HIV status, age, level of education, marital status, number of people and children in the household, feel safe at home, ever been arrested, family cohesion, sex work stigma domestic violence attitudes, number of days per week engaged in sex work and number of paying sexual partners). Participants' HIV status ( $b=-1.10,95 \% \mathrm{CI}=-2.16,-0.04, \mathrm{p} \leq .05)$ and family cohesion $(b=-0.11,95 \% \mathrm{CI}=-0.18,-0.04, \mathrm{p} \leq .01)$ were associated with lower levels of PTSD. Sex work stigma $(b=0.15,95 \% \mathrm{CI}$ $=0.09,0.21, \mathrm{p} \leq .001$ ) was associated with higher levels of PTSD.

In model 2, when we controlled for economic-level factors (financial distress, household assets, currently working for pay and number of income earners in the household), HIV status $(b=-1.16,95 \% \mathrm{CI}=-2.21$, 
Table 2

Regression Analysis Results: b (95\% CI)

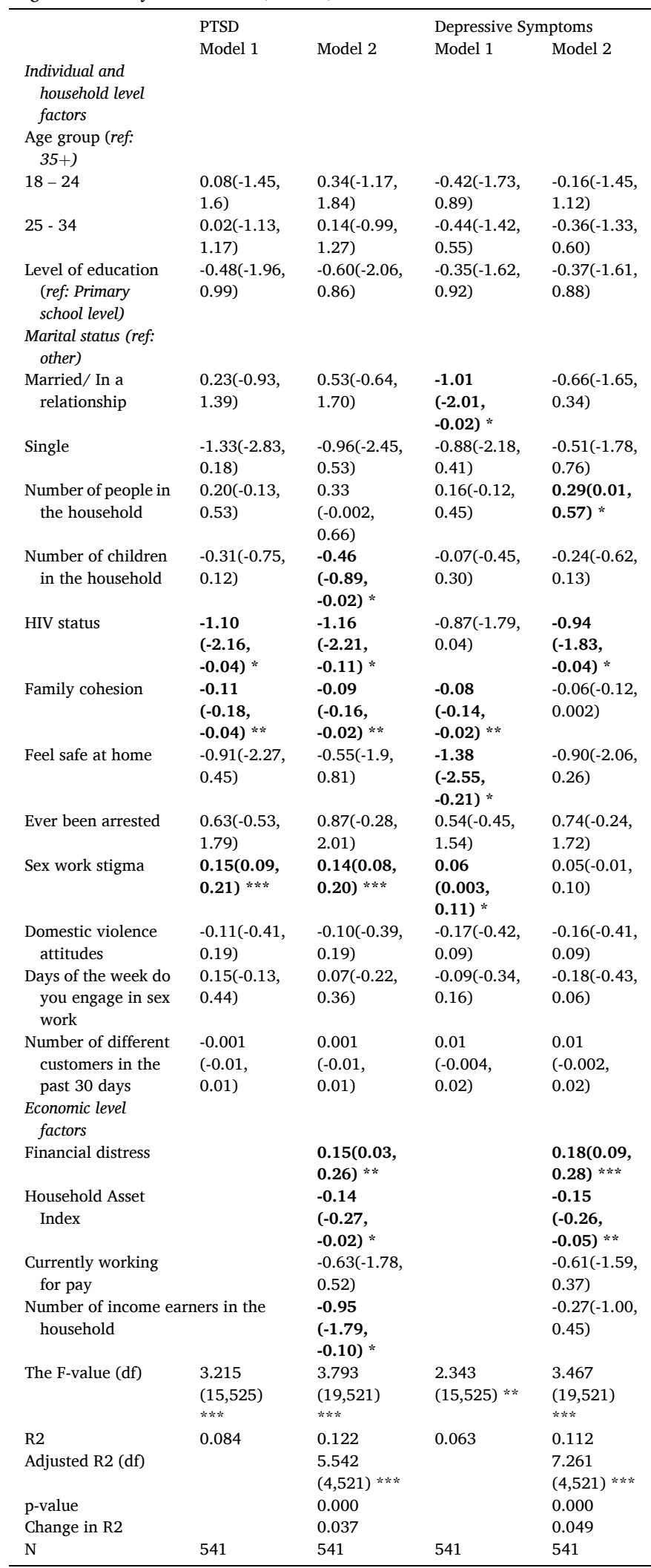

Note: ${ }^{*} \mathrm{p} \leq .05 ;{ }^{* *} \mathrm{p} \leq .01 ; * * * \mathrm{p} \leq .001$
$-0.11, \mathrm{p} \leq .05)$, family cohesion $(\mathrm{b}=-0.09,95 \% \mathrm{CI}=-0.16,-0.02$, $\mathrm{p} \leq .01)$ and sex work stigma $(\mathrm{b}=0.14,95 \% \mathrm{CI}=0.08,0.20, \mathrm{p} \leq .001)$ remained significant predictors of PTSD. In addition, number of children in the household $(\mathrm{b}=-0.46,95 \% \mathrm{CI}=-0.89,-0.02, \mathrm{p} \leq .05)$, household assets $(b=-0.14,95 \% \mathrm{CI}=-0.27,-0.02, \mathrm{p} \leq .05)$, and number of income earners in the household $(\mathrm{b}=-0.95,95 \% \mathrm{CI}=-1.79,-0.10, \mathrm{p} \leq .05)$ were all associated with lower levels of PTSD. On the other hand, financial distress $(b=0.15,95 \% \mathrm{CI}=0.03,0.26, \mathrm{p} \leq .01)$ were both associated with higher levels of PTSD. Model 1 explained $8.4 \%$ of the variance in PTSD $\left(R^{2}=0.084\right)$. When we added economic predictors, we were able to explain about $12.2 \%$ of the variance $\left(R^{2}=0.122\right)$. The additional $3.7 \%$ variance in PTSD was statistically significant $(\mathrm{p}<.001)$.

Additionally, being married $(\mathrm{b}=-1.01,95 \% \mathrm{CI}=-2.01,-0.02$, $\mathrm{p} \leq .05)$, family cohesion $(\mathrm{b}=-0.08,95 \% \mathrm{CI}=-0.14,-0.02, \mathrm{p} \leq .01)$ and feeling safe at home $(b=-1.38,95 \% \mathrm{CI}=-2.55,-0.21, \mathrm{p} \leq .05)$ were all associated with lower levels of depressive symptoms. Sex work stigma ( $b=0.06,95 \% \mathrm{CI}=0.00,0.11, \mathrm{p} \leq .05)$ was associated with depressive symptoms in model 1 . In the second model, we added economic factors and the results indicate that number of people in the household $(b=0.29$, $95 \% \mathrm{CI}=0.01,0.57, \mathrm{p} \leq .05)$ and financial distress $(\mathrm{b}=0.18,95 \% \mathrm{CI}$ $=0.09,0.28, \mathrm{p} \leq .001)$ were both associated with higher levels of depressive symptoms; while HIV status $(b=-0.94,95 \% C I=-1.83,-0.04$, $\mathrm{p} \leq .05)$ and household asset ownership $(\mathrm{b}=-0.15,95 \% \mathrm{CI}-0.26,-0.05$, $\mathrm{p} \leq .01)$ were associated with lower levels depressive symptoms. Model 1 explained $6 \%$ of the variance in depressive symptoms $\left(R^{2}=0.063\right)$. A combination of individual and economic-level factors explained about $11 \%$ of the variance $\left(R^{2}=0.112\right)$. The additional $4.9 \%$ variance in depressive symptoms was statistically significant $(\mathrm{p}<.05)$.

\section{Discussion}

This study utilized baseline data to examine the factors associated with depressive symptoms and PTSD among WESW. In our sample, $42 \%$ of study participants tested positive for HIV. This prevalence is very high, but consistent with previous studies that documented the prevalence of HIV among WESW in the study region (Ssembatya et al., 2015).

Family level factors, including family cohesion, feeling safe at home, number of people and children on the household, as well as marital status (being married) were associated with lower levels of either PTSD or depressive symptoms. These findings are consistent with previous studies that have documented that close and supportive relationships, especially with family members, as a protective factor against poor mental health outcomes (Achenbaum \& Carr, 2014; Fiori \& Denckla, 2012; House et a., 1988; Kogstad et al., 2013; Thomas et al., 2017), including among WESW (Carlson et al., 2017).

Consistent with previous studies, sex work stigma was associated with high levels of PTSD and depressive symptoms (Carlson et al., 2017; Stockton et al., 2020; Zehnder et al., 2019). Given that stigma deters individuals from seeking care (Gulliver et al., 2010; Nyblade et al., 2017; Rayson \& Alba, 2019; Scorgie et al., 2013; Zehnder et al., 2019) and adhering to treatment protocols (Denison et al., 2015; Dow et al., 2016; Koole et al., 2016), this finding points to the need to integrate stigma-reduction components in HIV programming targeting WESW to address mental health functioning.

Previous studies have documented a strong link between HIV and mental health functioning (Catalan et al., 2011; Chibanda at al., 2016; Hughes et al., 2016; Kane et al., 2019; Sherr et al., 2011). In our sample however, being HIV positive was associated with lower levels of PTSD and depressive symptoms. This result could be related to the psychosocial support that individuals living with HIV receive as part of the HIV. Specifically, the Uganda government's consolidated guidelines for the prevention and treatment of HIV/AIDS (Republic of Uganda, 2020), recommend psychosocial care and support as part of the "test and treat" policy to enhance adherence, retention and viral suppression. Individuals receive psychosocial care and support services packages, comprising of psychosocial screening and assessment, counseling and 
psychotherapy, mental health screening and support as well as referral and linkage to other support service among others. As such, it could be that participants receive some of these services, lowering their risk of poor mental health functioning.

Financial distress, including the inability to afford basic needs, was associated with higher levels of PTSD and depressive symptoms. This finding is consistent with previous studies that document poverty as a major risk factor for poor mental health outcomes (Lund et al., 2010; Patel et al., 2010; Stratford et al., 2008). On the other hand, having an additional income earner in the household, and availability of household assets were both associated with lower levels of depressive symptoms. Therefore, integrating economic strengthening components in the programs targeting WESW is critical to address their mental health wellbeing.

There are three major limitations to this study. First, the Beck Depression Inventory and the PTSD checklist serve primarily as screening tools. Scores are not meant to be interpreted as a diagnosis of depression or another mental health disorder -as this requires further assessment. Additionally, we used these measures to be consistent with our prior studies among WESW in LMIC, for purposes of comparability across studies. They were not originally intended for implementation in this region, however, and more sensitive and appropriate measures may be available (Ali et al. 2016). Second, data were self-reported by WESW and may have been influenced by social desirability biases to minimize or hide depressive symptoms. Third, we reported baseline, cross-sectional data only and are, therefore, unable to make any causal inferences.

\section{Conclusion}

Women engaged in commercial sex work are at a higher risk of HIV and poor mental health outcomes. Our study findings indicate that sex work stigma and financial distress elevate levels of depressive symptoms and post traumatic depressive disorder, over and above an individual's HIV status. However, family cohesion and economic-level factors, including household assets and number of income earners have the potential to mitigate the risk of poor mental health outcomes. Therefore, to address both the treatment needs of WESW and the subsequent behavioral health outcomes including mental health, it is important to integrate both mental health interventions and economic empowerment approaches in programming for WESW. Specifically, stigma reduction components, including those focused on HIV, mental health and sex work -as well as components focused on economic strengthening to reduce financial distress, to improve HIV prevention efforts and address mental health.

\section{Consent for publication}

Not Applicable

\section{Authors Contributions}

PN and WB wrote the manuscript. CD managed the study data and led the data analysis process. JK, JN coordinated the field activities. FMS and SSW wrote the grant and obtained funding for the study. OSB, LJM$\mathrm{W}, \mathrm{YT}, \mathrm{RB}$ reviewed the manuscript for intellectual content and made significant additions to the manuscript. All authors read and approved the final manuscript.

\section{Availability of data and materials}

The datasets analyzed during the current study are available from the corresponding author on reasonable request.

\section{Funding}

This work as supported by the National Institute of Mental Health (NIMH) under award number R01MH116768 (MPIs: Fred Ssewamala, $\mathrm{PhD} \&$ Susan Witte, PhD). NIMH had no role in the study design, data collection, analysis, interpretation of findings and preparing this manuscript. The content is solely the responsibility of the authors and does not necessarily represent the official views of NIMH or the National Institutes of Health.

\section{Competing Interests}

The authors declare that they have no competing interests

\section{Acknowledgements}

Our special thanks go to the WESW who have participated in the study and made this work possible. We are also grateful to the staff and volunteers at the International Center for Child Health and Development (ICHAD) in Uganda for coordinating the study; Reach the Youth Uganda; Rakai Health Sciences Program, the research teams at Columbia University in New York, New York University, and Indiana University; the Community Collaborative Board; and the Data and Safety Monitoring Board for their respective contributions to the study design and implementation. In addition, we are grateful to the financial institutions that agreed to work with our study participants to open up savings accounts, as well as community health workers who facilitated intervention delivery.

\section{REFERENCES}

Achenbaum, W.A., Carr, L.C., 2014. What social relationships can do for health. Generations 38 (2), 9-13.

Ali, G.C., Ryan, G., De Silva, M.J, 2016. Validated screening tools for common mental disorders in low- and middle-income countries: a systematic review. PloS one 11 (6), e0156939.

Ampt, F.H., Lim, M.S., Agius, P.A., L'Engle, K., Manguro, G., Gichuki, C., Luchters, S., 2020. Effect of a mobile phone intervention for female sex workers on unintended pregnancy in Kenya (WHISPER or SHOUT): a cluster-randomised controlled trial. The Lancet Global Health 8 (12) e1534-e1545.

Audu, I.A., Idris, S.H., Olisah, V.O., Sheikh, T.L., 2013. Stigmatization of people with mental illness among inhabitants of a rural community in northern Nigeria. International Journal of Social Psychiatry 59 (1), 55-60.

Baleta, A., 2015. Lives on the line: sex work in sub-Saharan Africa. The Lancet 385 (9962) e1-e2.

Baral, S., Beyrer, C., Muessig, K., Poteat, T., Wirtz, A.L., Decker, M.R., Kerrigan, D., 2012. Burden of HIV among female sex workers in low-income and middle-income countries: a systematic review and meta-analysis. The Lancet infectious diseases 12 (7), 538-549.

Beattie, T.S., Smilenova, B., Krishnaratne, S., Mazzuca, A., 2020. Mental health problems among female sex workers in low-and middle-income countries: A systematic review and meta-analysis. PLoS medicine 17 (9), e1003297.

Carlson, C.E., Witte, S.S., Pala, A.N., Tsai, L.C., Wainberg, M., Aira, T., 2017. The impact of violence, perceived stigma, and other work-related stressors on depressive symptoms among women engaged in sex work. Global social welfare 4 (2), 51-57.

Catalan, J., Harding, R., Sibley, E., Clucas, C., Croome, N., Sherr, L., 2011. HIV infection and mental health: suicidal behaviour-systematic review. Psychology, health \& medicine 16 (5), 588-611.

Chibanda, D., Cowan, F., Gibson, L., Weiss, H.A., Lund, C., 2016. Prevalence and correlates of probable common mental disorders in a population with high prevalence of HIV in Zimbabwe. BMC psychiatry 16 (1), 1-9.

Cowan, F.M., Davey, C., Fearon, E., Mushati, P., Dirawo, J., Chabata, S., Hargreaves, J.R., 2018. Targeted combination prevention to support female sex workers in Zimbabwe accessing and adhering to antiretrovirals for treatment and prevention of HIV (SAPPH-IRe): a cluster-randomised trial. The lancet HIV 5 (8) e417-e426.

Deering, K.N., Amin, A., Shoveller, J., Nesbitt, A., Garcia-Moreno, C., Duff, P., Shannon, K., 2014. A systematic review of the correlates of violence against sex workers. American journal of public health 104 (5) e42-e54.

Denison, J.A., Koole, O., Tsui, S., Menten, J., Torpey, K., Van Praag, E., Bangsberg, D.R., 2015. Incomplete adherence among treatment-experienced adults on antiretroviral therapy in Tanzania, Uganda and Zambia. AIDS (London, England) 29 (3), 361.

Derogatis, L.R., Melisaratos, N., 1983. The brief symptom inventory: an introductory report. Psychological medicine 13 (3), 595-605.

Dow, D.E., Turner, E.L., Shayo, A.M., Mmbaga, B., Cunningham, C.K., O’Donnell, K, 2016. Evaluating mental health difficulties and associated outcomes among HIVpositive adolescents in Tanzania. AIDS care 28 (7), 825-833. 
Fielding-Miller, R., Mnisi, Z., Adams, D., Baral, S., Kennedy, C., 2014. There is hunger in my community": a qualitative study of food security as a cyclical force in sex work in Swaziland. BMC public health 14 (1), 1-10.

Fiori, K.L., Denckla, C.A., 2012. Social support and mental health in middle-aged men and women: a multidimensional approach. Journal of Aging and Health 24 (3), 407-438.

Goel, S., Salganik, M.J., 2009. Respondent-driven sampling as Markov chain Monte Carlo. Statistics in medicine 28 (17), 2202-2229.

Gulliver, A., Griffiths, K.M., Christensen, H., 2010. Perceived barriers and facilitators to mental health help-seeking in young people: a systematic review. BMC psychiatry 10 (1), 1-9.

Han, C.K., Ssewamala, F.M., Wang, J.S.H, 2013. Family economic empowerment and mental health among AIDS-affected children living in AIDS-impacted communities: evidence from a randomised evaluation in southwestern Uganda. J Epidemiol Community Health 67 (3), 225-230.

House, J.S., Landis, K.R., Umberson, D., 1988. Social relationships and health. Science 241 (4865), 540-545.

Hughes, E., Bassi, S., Gilbody, S., Bland, M., Martin, F., 2016. Prevalence of HIV, hepatitis $\mathrm{B}$, and hepatitis $\mathrm{C}$ in people with severe mental illness: a systematic review and meta-analysis. The Lancet Psychiatry 3 (1), 40-48.

Kagotho, N., Ssewamala, F.M., 2012. Correlates of depression among caregivers of children affected by HIV/AIDS in Uganda: Findings from the Suubi-Maka Family Study. AIDS Care 24 (10), 1226-1232.

Kamali, A., Nsubuga, R.N., Ruzagira, E., Bahemuka, U., Asiki, G., Price, M.A., Fast, P., 2016. Heterogeneity of HIV incidence: a comparative analysis between fishing communities and in a neighbouring rural general population, Uganda, and implications for HIV control. Sexually transmitted infections 92 (6), 447-454.

Kapungwe, A., Cooper, S., Mwanza, J., Mwape, L., Sikwese, A., Kakuma, R., Flisher, A.J., 2010. Mental illness-stigma and discrimination in Zambia. African Journal of Psychiatry 13 (3).

Kane, J.C., Elafros, M.A., Murray, S.M., Mitchell, E.M., Augustinavicius, J.L. Causevic, S., Baral, S.D., 2019. A scoping review of health-related stigma outcomes for high-burden diseases in low-and middle-income countries. BMC medicine 17 (1), $1-40$.

Kigozi, F., Ssebunnya, J., Kizza, D., Cooper, S., Ndyanabangi, S., 2010. An overview of Uganda's mental health care system: results from an assessment using the world health organization's assessment instrument for mental health systems (WHOAIMS). International Journal of Mental Health Systems 4 (1), 1-9.

Koenig, M.A., Lutalo, T., Zhao, F., Nalugoda, F., Kiwanuka, N., Wabwire-Mangen, F., Gray, R., 2004. Coercive sex in rural Uganda: prevalence and associated risk factors. Social Science \& Medicine 58 (4), 787-798.

Kogstad, R.E., Mönness, E., Sörensen, T., 2013. Social networks for mental health clients: Resources and solution. Community mental health journal 49 (1), 95-100.

Koole, O., Denison, J.A., Menten, J., Tsui, S., Wabwire-Mangen, F., Kwesigabo, G., Colebunders, R., 2016. Reasons for missing antiretroviral therapy: results from a multi-country study in Tanzania, Uganda, and Zambia. PloS one 11 (1), e0147309.

Lang, A.J., Stein, M.B., 2005. An abbreviated PTSD checklist for use as a screening instrument in primary care. Behaviour research and therapy 43 (5), 585-594.

Liu, S.H., Srikrishnan, A.K., Zelaya, C.E., Solomon, S., Celentano, D.D., Sherman, S.G., 2011. Measuring perceived stigma in female sex workers in Chennai, India. AIDS care 23 (5), 619-627.

Lund, C., Alem, A., Schneider, M., Hanlon, C., Ahrens, J., Bandawe, C., Susser, E., 2015 Generating evidence to narrow the treatment gap for mental disorders in subSaharan Africa: rationale, overview and methods of AFFIRM. Epidemiology and Psychiatric Sciences 24 (3), 233-240.

Lund, C., Breen, A., Flisher, A.J., Kakuma, R., Corrigall, J., Joska, J.A., Patel, V., 2010. Poverty and common mental disorders in low- and middle-income countries: A systematic review. Social science \& medicine 71 (3), 517-528.

Lundberg, P., Rukundo, G., Ashaba, S., Thorson, A., Allebeck, P., Östergren, P.O., CantorGraae, E., 2011. Poor mental health and sexual risk behaviours in Uganda: a crosssectional population-based study. BMC Public Health 11 (1), 1-10.

Mathers, C.D., Loncar, D., 2006. Projections of global mortality and burden of disease from 2002 to 2030. PLoS medicine 3 (11), e442.

Mergenova, G., El-Bassel, N., McCrimmon, T., Terlikbayeva, A., Primbetova, S., Riedel, M., Witte, S.S., 2019. Project Nova: a combination HIV prevention and microfinance intervention for women who engage in sex work and use drugs in Kazakhstan. AIDS and Behavior 23 (1), 1-14.

Mgbako, C., Smith, L.A., 2009. Sex work and human rights in Africa. Fordham Int'l LJ 33, 1178.

Molodynski, A., Cusack, C., Nixon, J., 2017. Mental healthcare in Uganda: desperate challenges but real opportunities. BJPsych International 14 (4), 98-100.

Moos, R.H., 1994. Family environment scale manual: Development, applications, research. Consulting Psychologists Press.

Morris, C.N., Ferguson, A.G., 2006. Estimation of the sexual transmission of HIV in Kenya and Uganda on the trans-Africa highway: the continuing role for prevention in highrisk groups. Sexually transmitted infections 82 (5), 368-371.

Mugisha, J., Ssebunnya, J., Kigozi, F.N., 2016. Towards understanding governance issues in integration of mental health into primary health care in Uganda. International Journal of Mental Health Systems 10 (1), 1-14.

Nabunya, P., Ssewamala, F.M., Ilic, V., 2014. Family economic strengthening and parenting stress among caregivers of AIDS-orphaned children: results from a cluster randomized clinical trial in Uganda. Children and Youth Services Review 44, 417-421.

Nduna, M., Jewkes, R.K., Dunkle, K.L., Shai, N.P.J., Colman, I, 2010. Associations between depressive symptoms, sexual behaviour and relationship characteristics: a prospective cohort study of young women and men in the Eastern Cape, South Africa. Journal of the International AIDS Society 13 (1), 1-8.

Nyblade, L., Reddy, A., Mbote, D., Kraemer, J., Stockton, M., Kemunto, C., Barker, C., 2017. The relationship between health worker stigma and uptake of HIV counseling and testing and utilization of non-HIV health services: the experience of male and female sex workers in Kenya. AIDS Care 29 (11), 1364-1372.

Okal, J., Raymond, H.F., Tun, W., Musyoki, H., Dadabhai, S., Broz, D., Geibel, S., 2016. Lessons learned from respondent-driven sampling recruitment in Nairobi: experiences from the field. BMC Research Notes 9 (1), 1-13.

Onyeneho, N.G., 2009. HIV/AIDS risk factors and economic empowerment needs of female sex workers in Enugu Urban, Nigeria. Tanzania Journal of Health Research 11 (3).

Opio, A., Muyonga, M., Mulumba, N., 2011. HIV sero behavioral survey in fishing communities of the Lake Victoria basin of Uganda. SIDA,MOH, AMREF, Stockholm.

Parcesepe, A.M., L'Engle, K.L., Martin, S.L., Green, S., Suchindran, C., Mwarogo, P, 2016. Early sex work initiation and violence against female sex workers in Mombasa, Kenya. Journal of Urban Health 93 (6), 1010-1026.

Patel, V., 2007. Mental health in low-and middle-income countries. British Medical Bulletin 81 (1), 81-96.

Patel, V., Kleinman, A., 2003. Poverty and common mental disorders in developing countries. Bulletin of the World Health Organization 81, 609-615.

Patel, V., Lund, C., Hatherill, S., Plagerson, S., Corrigall, J., Funk, M., Flisher, A.J., 2010. Mental disorders: equity and social determinants. Equity, social determinants and public health programmes 115, 134.

Platt, L., Grenfell, P., Meiksin, R., Elmes, J., Sherman, S.G., Sanders, T., Crago, A.L., 2018. Associations between sex work laws and sex workers' health: A systematic review and meta-analysis of quantitative and qualitative studies. PLoS Medicine 15 (12), e1002680.

Rathod, S., Pinninti, N., Irfan, M., Gorczynski, P., Rathod, P., Gega, L., Naeem, F., 2017. Mental health service provision in low-and middle-income countries. Health services insights 10, 1178632917694350.

Rayson, J., Alba, B., 2019. Experiences of stigma and discrimination as predictors of mental health help-seeking among sex workers. Sexual and Relationship Therapy 34 (3), 277-289.

Republic of Uganda, 2020. Consolidated Guidelines for Prevention and Treatment of HIV in Uganda. Accessed February 11, 2021 from: https://uac.go.ug/sites/default/files/ Consolidated\%20HIV\%20Guidelines\%202020.pdf.

Republic of Uganda, 2018. Report on National AIDS Spending Assessment study. Retrieved September 1, 2020 from: https://uac.go.ug/sites/default/files/NASA\% 20Report\%202019.pdf.

Scorgie, F., Nakato, D., Harper, E., Richter, M., Maseko, S., Nare, P., Chersich, M., 2013. We are despised in the hospitals': sex workers' experiences of accessing health care in four African countries. Culture, health \& sexuality 15 (4), 450-465.

Seeley, J., Tumwekwase, G., Grosskurth, H., 2009. Fishing for a living but catching HIV: AIDS and changing patterns of the organization of work in fisheries in Uganda. Anthropology of Work Review 30 (2), 66-76.

Sherr, L., Clucas, C., Harding, R., Sibley, E., Catalan, J., 2011. HIV and depression-a systematic review of interventions. Psychology, health \& medicine 16 (5), 493-527.

Sirotin, N., Strathdee, S.A., Lozada, R., Abramovitz, D., Semple, S.J., Bucardo, J., Patterson, T.L., 2010. Effects of government registration on unprotected sex amongst female sex workers in Tijuana; Mexico. International journal of drug policy 21 (6), 466-470.

Skinner, H.A., Steinhauer, P.D., Santa-Barbara, J., 2009. The family assessment measure. Canadian Journal of Community Mental Health 2 (2), 91-103.

Smit, J., Myer, L., Middelkoop, K., Seedat, S., Wood, R., Bekker, L.G., Stein, D.J., 2006. Mental health and sexual risk behaviours in a South African township: a communitybased cross-sectional study. Public health 120 (6), 534-542.

Ssebunnya, J., Kigozi, F., Lund, C., Kizza, D., Okello, E., 2009. Stakeholder perceptions of mental health stigma and poverty in Uganda. BMC International Health and Human Rights 9 (1), 1-9.

Ssembatya, J.L., Kagaayi, J., Ssemanda, J.B., Kairania, R., Kato, E., Nalubega, I., et al., 2015. Interventions for commercial sexual workers: lessons and challenges from Rakai, Uganda. In: Proceedings of the 8th AIS Conference on HIV Pathogenesis, Treatment and Prevention. Vancouver, British Columbia, Canada.

Ssewamala, F.M., Bahar, O.S., Tozan, Y., Nabunya, P., Mayo-Wilson, L.J., Kiyingi, J., Witte, S.S., 2019. A combination intervention addressing sexual risk-taking behaviors among vulnerable women in Uganda: study protocol for a cluster randomized clinical trial. BMC women's health 19 (1), 1-21.

Ssewamala, F.M., Han, C.K., Neilands, T.B., 2009. Asset ownership and health and mental health functioning among AIDS-orphaned adolescents: Findings from a randomized clinical trial in rural Uganda. Social science \& medicine 69 (2), $191-198$.

Stark, L., Seff, I., Asghar, K., Roth, D., Bakamore, T., MacRae, M., Falb, K.L., 2018. Building caregivers' emotional, parental and social support skills to prevent violence against adolescent girls: findings from a cluster randomised controlled trial in Democratic Republic of Congo. BMJ global health 3 (5).

Stratford, D., Mizuno, Y., Williams, K., Courtenay-Quirk, C., O'leary, A., 2008. Addressing poverty as risk for disease: recommendations from CDC's consultation on microenterprise as HIV prevention. Public health reports 123 (1), 9-20.

Stockton, M.A., Pence, B.W., Mbote, D., Oga, E.A., Kraemer, J., Kimani, J., Nyblade, L., 2020. Associations among experienced and internalized stigma, social support, and depression among male and female sex workers in Kenya. International journal of public health 65 (6), 791-799.

Thomas, P.A., Liu, H., Umberson, D., 2017. Family relationships and well-being. Innovation in aging 1 (3), 1-11. 
Tsai, L.C., Witte, S.S., Aira, T., Altantsetseg, B., Riedel, M., 2011. Piloting a savings-led microfinance intervention with women engaging in sex work in Mongolia: Further innovation for HIV risk reduction. The open women's health journal 5, 26.

Tsai, L.C., Witte, S.S., Aira, T., Riedel, M., Offringa, R., Chang, M., 2018. Efficacy of a microsavings intervention in increasing income and reducing economic dependence upon sex work among women in Mongolia. International Social Work 61 (1), 6-22.

UNAIDS, 2002. Sex work and HIV/AIDS. Retrieved February 8, 2021 from: https://data. unaids.org/publications/irc-pub02/jc705-sexwork-tu_en.pdf.

Uganda AIDS Commission (2020). Facts on HIV and AIDS in Uganda 2020. Retrieved September 1, 2020 from: https://uac.go.ug/sites/default/files/Reports/2020\% 20FACT\%20SHEET.pdf.

Uganda AIDS Commission, 2015. National HIV and AIDS Strategic Plan 2015/2016 2019-2020. An AIDS Free Uganda, My responsibility. Retrieved September 1, 2020, https://uac.go.ug/sites/default/files/National\%20HIV\%20and\%20AIDS\% 20Strategic\%20Plan\%202015-2020.pdf.

Wang, J.S.H., Ssewamala, F.M., Han, C.K, 2014. Family economic strengthening and mental health functioning of caregivers for AIDS-affected children in rural Uganda. Vulnerable Children and Youth Studies 9 (3), 258-269.
WHO, 2018. Mental Health ATLAS 2017. Retrieved February 10, 2021, from: https:// apps.who.int/iris/bitstream/handle/10665/272735/9789241514019-eng.pdf? ua $=1$.

WHO, 2013. Mental Health Action Plan 2013-2020 (extended to 2030). Retrieved February 10, 2021 from: https://apps.who.int/iris/handle/10665/89966.

Witte, S.S., Aira, T., Tsai, L.C., Riedel, M., Offringa, R., Chang, M., Ssewamala, F., 2015. Efficacy of a savings-led microfinance intervention to reduce sexual risk for HIV among women engaged in sex work: a randomized clinical trial. American Journal of Public Health 105 (3) e95-e102.

Witte, S.S., Altantsetseg, B., Aira, T., Riedel, M., Chen, J., Potocnik, K., Yao, H., 2011. Reducing sexual HIV/STI risk and harmful alcohol use among female sex workers in Mongolia: a randomized clinical trial. AIDS and Behavior 15 (8), 1785-1794.

Yatham, S., Sivathasan, S., Yoon, R., da Silva, T.L., Ravindran, A.V., 2018. Depression, anxiety, and post-traumatic stress disorder among youth in low- and middle-income countries: a review of prevalence and treatment interventions. Asian Journal of Psychiatry 38, 78-91.

Zehnder, M., Mutschler, J., Rössler, W., Rufer, M., Rüsch, N., 2019. Stigma as a barrier to mental health service use among female sex workers in Switzerland. Frontiers in psychiatry 10, 32 . 